\title{
Automatic Calf Feeder System
}

\author{
Mihaela Hnatiuc and Mugurel Caracostea
}

\begin{abstract}
Automatic calf feeder system is designed to replace the human work in several areas. Increasing the quality and quantity in zootechnic and agricultural productions can be achieved by using sensing tech to make farms intelligent. In this paper is presented the automatic and autonomous system for calf feeding, controlled with microcontroller card, sensors and software interface. In the dairy farming, replaced milk calf ratios are limited to one or two portions a day, in case of manual feeding. The fuzzy system used can predict the recipe of mixture using several input parameters as group, age, weight, behavior and speed of feeding. The input-output parameters are identified after testing of the automatic system described in the first part of the paper. The fuzzy technique is applied to determine the nutrition requirement and the quantity of food intake that needs to be fed, after a couple of days of using the system. Some important parameters of the feeding behavior of calves such as frequency, speed or ablactation time spent on feeding station, sets an alarm triggered into the system.
\end{abstract}

Index Terms-Automatic system, knowledge based system, feeding system, user interface, behavior identification.

\section{INTRODUCTION}

Automated systems for feeding calves controlled by computer are in great demand because of the benefits of saving labour. This system consists of a stand-alone unit that heats water and dispense a preset powder milk quantity and mix it, then transfer in a glass cylinder from which the calf can be fed from feeding station via the teat [1], [2]. The system would provide the ability to feed two groups of 25 calves each for up to 10 weeks. In the first 7 to 10 days, calves will be fed with bottle teat in order to familiarize with automatic feeding systems. It has been observed that calves spend 30 to 50 minutes a day at the feeding station. Anyone who wants to get cows to produce milk quality for an extended period must first optimize the rearing of calves. Automated compact calf distributor guarantees optimum growth and development of these young animals [3]. Calves can still enjoy their natural rhythm and can drink whenever they want, in a controlled manner while working to minimize staff. It has developed automated systems that set the right numbers of meals with proper concentration, throughout the day, like rhythm in feeding calves. When a calf enters in the feeding station, RFID tag placed on the ear is recognized by receiver antenna placed on side of feeding station and start preparing adequate recipe to calf's age as well adding

Manuscript received March 28, 2017; revised May 31, 2017. This work was supported in part by Association for Promoting Electronic Technology and AFCEA International.

The authors are with the Department of Electronic and Telecommunication, Electromechanics Faculty, Constanta Maritime University, Romania (e-mail: mihaela.hnatiuc@cmu-edu.eu, elmugur@gmail.com). vitamins or antibiotics according to state of sickness. All recipes can be accessed from software menu and manually adjust quantities according to powder milk supplier recommendations. If the calf is allowed to be fed, the system immediately start prepare according to the specified recipe. Automated system for calves feeding allows the farmer an economy of labor, thus providing considerable economic benefits them an exceptional start.

The benefits of the automatic nutrition are: accelerated growth rate, a better development of the rumen, manage individual calves, constant and precise temperature milk, flexible hours feeding, weaning without stress, flexibility of work, time economy, suitable for farms of all sizes, reliable, low maintenance. The research in this direction are developed to do the adaptable system for feeding process. The ration has consistent limitation, the fuzzy systems for chemical compositions of mixture are developed [4], [5]. An intelligent system based on fuzzy rules is developed to identify the cattle disease [6], the number of feeding per day [7]-[9].

Using the literature presentation, we have developed an automatic system for calves feeding and we propose an intelligent system to identify calf behavior which help in the mixture preparation and the alarm system.

To insert images in Word, position the cursor at the insertion point and either use Insert | Picture | From File or copy the image to the Windows clipboard and then Edit Paste Special | Picture (with "Float over text" unchecked).

\section{SYSTEM DESCRIPTION}

The control system of calf feeder developed has a hardware and software part. The hardware is based on an electronic card with relays and the microcontroller DsPIC30F4011 type (Fig. 1). The microcontroller receives the data from the sensors and commands the relays.

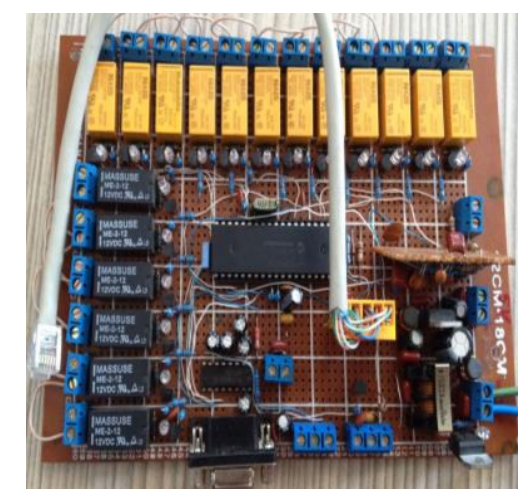

Fig. 1. The control and acquisition card based on relays.

The system is built for two feeding stations but is suitable as well to four stations in order to be used in farms with more 
than 100 calves. The relays control the vanes, pumps, and mixer motor. Using a screw conveyor motor the proper amount of powder milk is sent into the mixer. The boiler heats the water at $670 \mathrm{C}$. All the composition is mixed and then transferred to via the flowmeter to the teat into the feeding station.

The inputs components of the system are: temperature sensor for milk delivered to teat from feeding station 1 (TH1), temperature sensor for milk delivered to teat from feeding station 2 (TH2), flowmeter for water entering the mixer (DM1), prepared milk flowmeter sent to glass cylinder tank 1 or 2 (DM2, DM3) and a level sensor inside mixer receptacle. The outputs components are electro-valves (EV1 $\div 12$ ), peristaltic pumps (PP1, PP2 and PP3), mixer water feeding pump (P1), transfer pump to glass cylinder tanks (P2), waste water discharge pump resulted after washing cycle from station 1 or 2 (P3 or P4), screw conveyor motor for powder milk, the mixer motor, the water heater resistance - boiler (R1) (Fig. 2).

In the automatic calf feeder systems, amount of water/powder milk and vitamins or antibiotic drug treatment added are established by user using the software interface. After identifying the calf, the automated system by using relays open or close valves for mixed feed water and powder milk, substitutes and/or medicine drug and start preparing the adequate recipe.

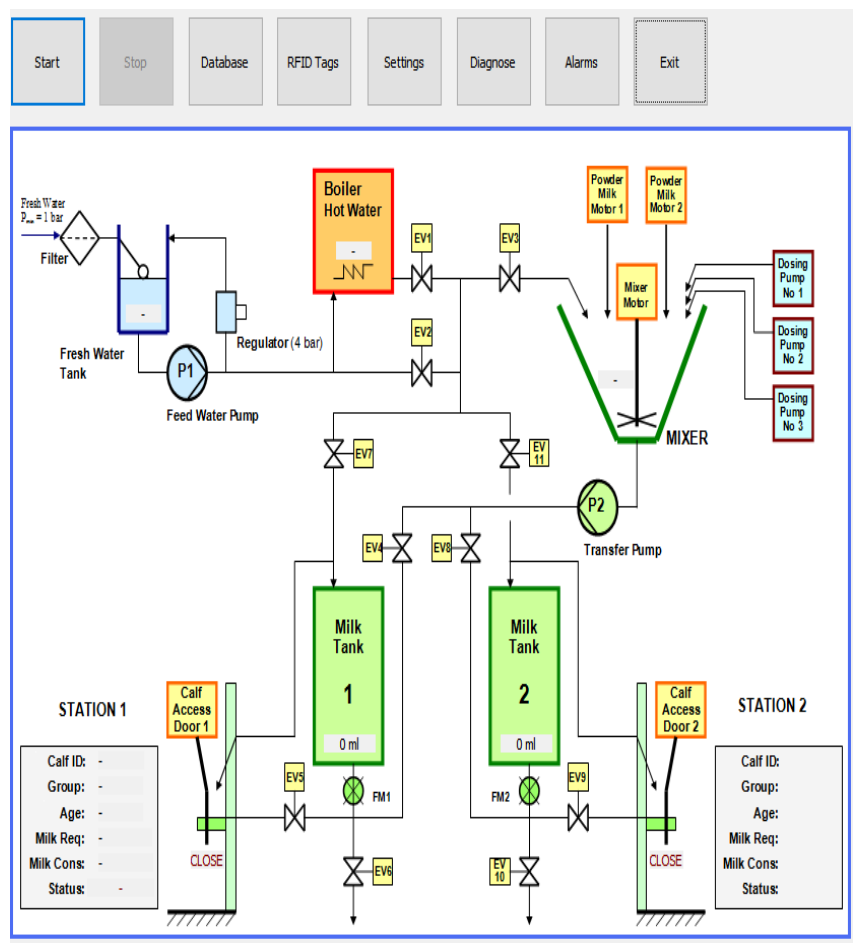

Fig. 2. The human-machine interface.

All the calves have RFID Tag to be identified by the system receiver antenna which is placed on the side of each feeding station. After tag identification, the microcontroller sent signals through relays: to screw conveyor to transfer the required powder milk into the mixer, to dosing pump in order to pour hot and/or cold water, to the mixer and to vitamins and drug dosing pumps. The preparing mixture is according to the age of the calves and health condition.

A human-machine interface is developed to command and monitor the feeding system (Fig. 2). The user can read the following information about the two feeding stations: Last visit; next visit; concentration of additive and mixture; additive dosing pump 1; Additive dosing pump 2; additive dosing pump 3; Feeding rate; feeding time, calf ID; group; age; amount of milk established; amount of consumed milk; condition of calf.

The information from RFID sensors signal is filtered using a Kalman Filter Method, to identify only the ID of the calf entered into the feeding station. The Kalman filter is a recursive estimator, it is the optimal minimum mean square error (MMSE) estimator for linear, Gaussian systems. This filter gives good fit for the measurements in a statistic, it is used for cut the noise of temperature, pressure or magnetic field signals.

\section{THE USER INTERFACE DESCRIPTION}

The interface developed in Visual C++ software has many front pages as: START, STOP, Database, RFID Tag, Diagnose, Alarm and Exit. Each feeding station is controlled from the same software interface via HMI.

The "Database" menu allows access to the database where you can see the activities of each group of calves, and each calf individually, age, last visit, next visit and prescription feeding - recipes (Fig. 3.). In this menu, the user can set Sick Calf flag or Suspend Ablactation. The calves are classified in many categories function of healthy condition and the future need (used for meat or for gestation, et. al.).

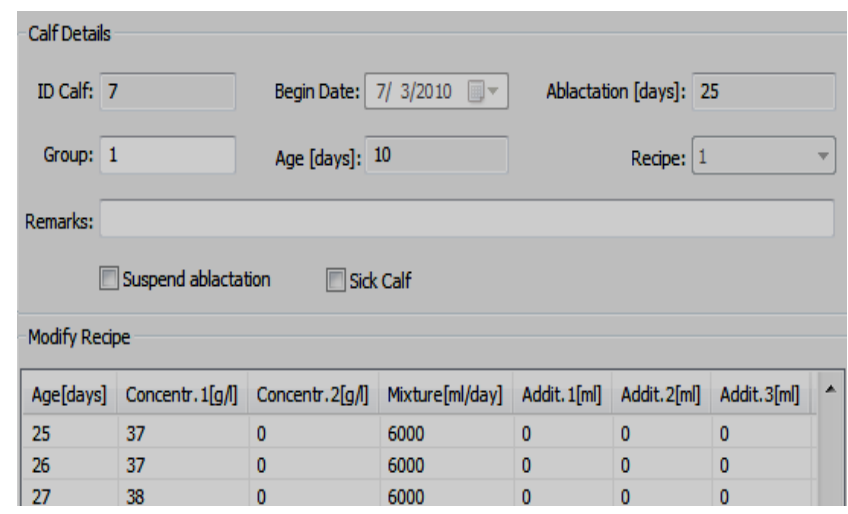

Fig. 3. The database menu which give information about each calf

The "RFID Tags" menu for adding or removing calves in list corresponding feeding station (Fig. 4).

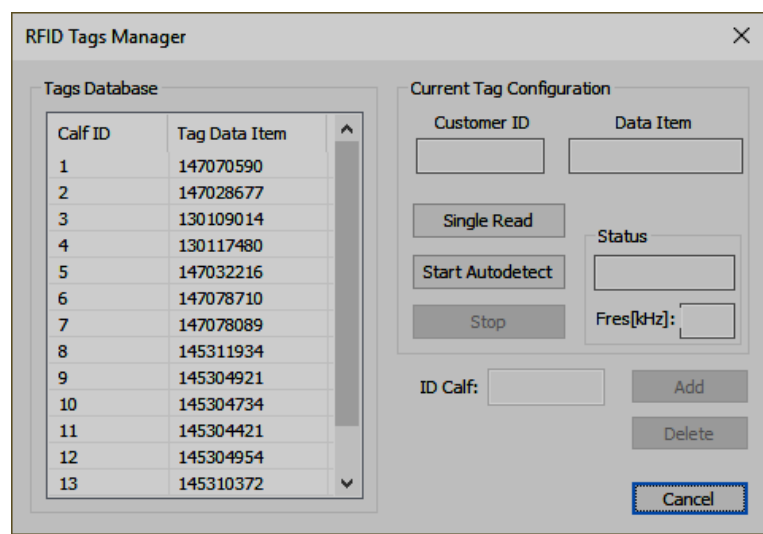

Fig. 4. The menu RFID Tags Manager for setting tags. 
The application allows inspection of the equipment by accessing the button "Diagnose" where the individual devices can be tested in Service Mode (Fig. 5).

There is a menu dedicate to alarms and setting values. The "Setting" menu can initialize the time parameters for mixture preparation $[\mathrm{s}]$ and for fed times:

- The feeding parameters: pump water flow [m/s], pump transfer flow $[\mathrm{m} / \mathrm{s}]$, cold water flow $[\mathrm{m} / \mathrm{s}]$, hot water flow $[\mathrm{m} / \mathrm{s}]$, pump metering flow 1,2 and $3[\mathrm{ml} / \mathrm{min}]$, powder milk flow $[\mathrm{g} / \mathrm{min}]$, mixing time [s], liquid transferred and evacuated flow [imp/l].

- Parameters feeding which the user can set are: beginning feeding program [hours / 24], closing feeding program [hours / 24], interval between feeding [hour/24].

- The calibration parameters are: time between two temperature reading [s], time of valves opening [s].

The open time of electro-valve is the key element in setting the quantities used in recipe.

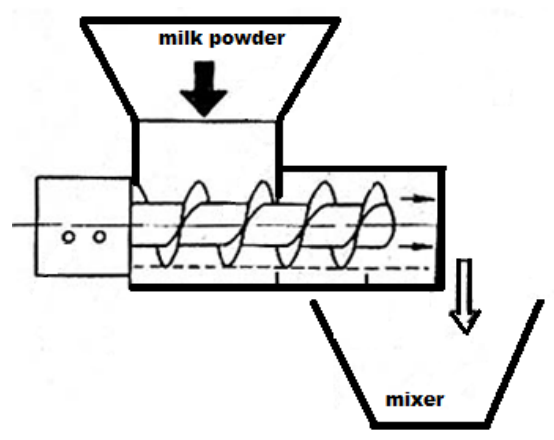

Fig. 5. Screw conveyor motor.

Dosage of quantities are made by the using the time quanta The water pressure regulator is set at 4 bar. As known, the water volume changes depending on temperature. To calculate the amount of milk from the Calves Database menu then selecting Recipes submenu the amounts used can be determined depending on the recipe optimal for calf age and depending on the consistencies of milk powder, and depending on the amount of water heated to $630 \mathrm{C}$, and the amount of cold water added to complete the recipe required. Depending on the identification tag RFID exactly the right amount of milk powder to be obtained by dividing the engine revs of the transfer box engaging the screw conveyor axis (Fig. 6).

The amount of powder milk is computed using the motor rotation. Working capacity $(\mathrm{Q}[\mathrm{T} / \mathrm{h}])$ of the screw conveyor is determined by the relationship:

$$
Q=p^{*} n * \gamma * C * k * 60 *\left(D^{2}-d^{2}\right) / 4
$$

where:

$D$ - internal diameter of the transporting pipe [m];

$d$ - diameter of the turning shaft $[\mathrm{m}]$;

$\gamma$ - bulk weight of the product [t/m3];

$C$ - Filling coefficient (usually for milk powder is 0.30 );

$k$ - correction coefficient depending on the angle of the conveyor $(\mathrm{k}=1$ to $00 ; \mathrm{k}=0.90$ to 50 angle and $\mathrm{k}=0.65$ to 200 angle)

$n$ - the screw rotation speed is between $60-125 \mathrm{rev} / \mathrm{min}$ for powder milk
After various testing on the field the water quantities through the flowmeter is calculated using $52224 \mathrm{imp} \mathrm{/}$ $261120 \mathrm{ml}$.

Via Diagnose menu we can calibrate the liquid through flowmeter Fig. 6.

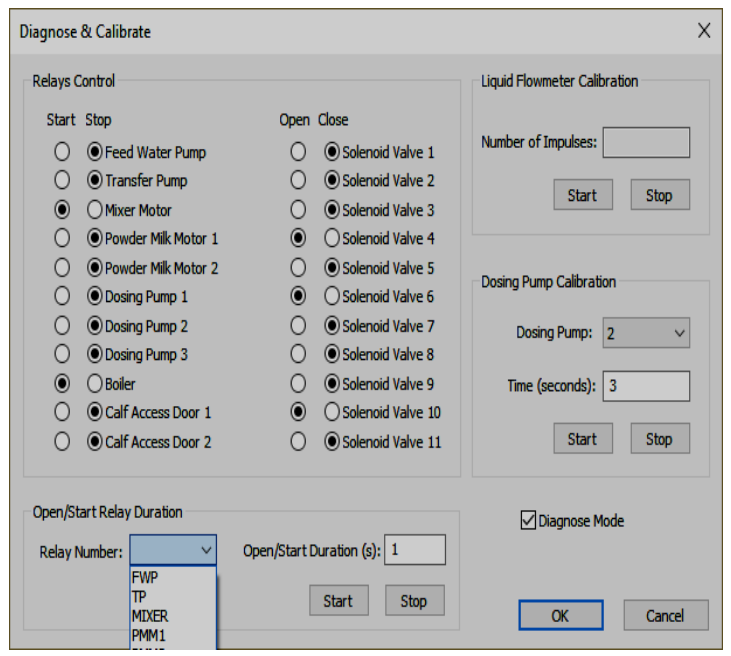

Fig. 6. Diagnose and calibrate menu.

According to powder milk concentration received from various suppliers is important to have possibility to adjust mixing rates, all from Database Menu accessing Recipes Common mixing rates are 115-180 g/l. If the automated calf feeder is set to mix $165 \mathrm{~g} / \mathrm{l}$, basic chemistry would say that the solid's percentage will be $16.5 \%$ by $165 \mathrm{~g}$ dissolved into volume of $1000 \mathrm{ml}$ results $1165 \mathrm{~g}$ solution. In reality the powder added to a volume of one litre of water, so the solid's percentage of 165 grams/L is actually less $14.16 \%$.

$165 / 1165=14.16 \%$

The equation used to calculate solids percentage is:

$\mathrm{S}$ measured in $\mathrm{g} / \mathrm{l}$

$S=($ powder.mix.rate $) /($ powder.mix.rate +1000$)) * 100$

Total quantity fed for calves [1/day]: usually daily fed volumes are 4-12 1/calf, depending on recipe. If powder milk is mixed at $165 \mathrm{~g} / \mathrm{l}$ and calves recipe is set to allow $6 \mathrm{l} / \mathrm{day}$, total milk powder will be $990 \mathrm{~g}$.

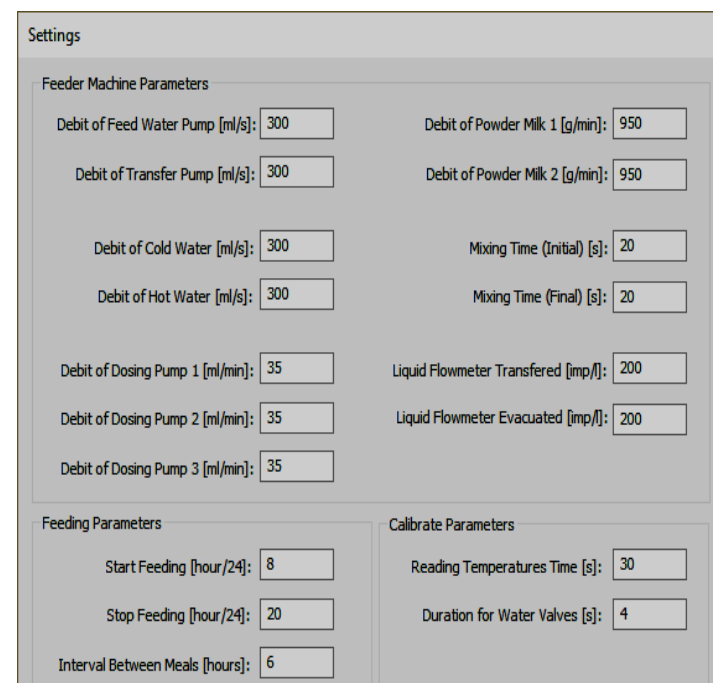

Fig. 7. The settings menu.

The menu dedicated for the "Alarms" (Fig. 8.), the user 
can add new alarms.

\begin{tabular}{|l|l|}
\hline ID & ALARM \\
\hline 1 & Hot Water Temperature - LOW \\
\hline 2 & Hot Water Temperature - LOW SHUTDOWN \\
3 & Cold Water Temperature - HIGH \\
\hline 4 & Cold Water Temperature - HIGH SHUTDOWN \\
\hline 5 & Mixture Temperature when Mixing - LOW \\
\hline 6 & Mixture Temperature when Mixing - LOW SHUTDOWN \\
7 & Mixture Temperature when Mixing - HIGH \\
8 & Mixture Temperature when Mixing - HIGH SHUTDOWN \\
9 & Mixture Temperature - LOW \\
\hline 10 & Mixture Temperature - LOW SHUTDOWN \\
11 & Mixture Temperature - HIGH \\
\hline 12 & Mixture Temperature - HIGH SHUTDOWN \\
\hline 13 & Mixture Transfer Pump - TIME OUT \\
14 & Liquid Flowmeter No. 1 - FAIL \\
\hline 15 & Liquid Flowmeter No. 2 - FAIL \\
\hline 16 & Hot Water - NO WATER \\
\hline 17 & Cold Water - NO WATER \\
\hline
\end{tabular}

Fig. 8. The alarms list in menu alarm.

\section{The Algorithm of Automatic Feeding Calves}

The steps of the feeding process are (Fig. 7):

1. Calf identification - if the calf didn't eat Open the access door on the feeding station;

2. Mixture preparation:

2.1. Prepare the hot water $(670 \mathrm{C})$ and open the pump P1 and valve EV1, EV2, EV3;

2.2. The milk powder mixture preparation;

2.3. Start the mixer;

2.4. Introduce the additives;

2.5. Input the hot/cold water;

2.6. Continuing mixing until the end of time set

3. Transfer the milk in into glass cylinder tank;

3.1 Start the pump P2 and open the valve EV4 or EV8

3.2 Counting the milk amount using flowmeter FM1 or

FM2; If the flowmeter signal is stop - set alarm flag else close valve EV4 and EV8 and STOP transfer pump;

4. Calf Feeding

4.1. Open the valve EV5 or EV9;

4.2. Counting the milk quantity eaten by calf;

4.3. When finished close the valve EV5 and EV9 and shut off access gate to teat;

5. Washing process: first wash is with boiled hot water and the second one with cold water in order to minimize transfer of diseases from calf to calf;

This system is developed with an individual program of feeding in which each calf has own inputs parameters (Fig. 9).

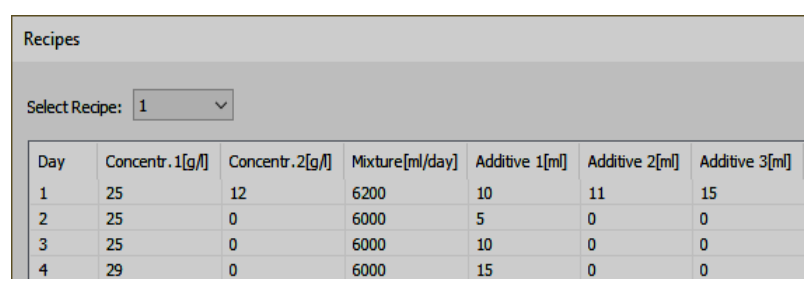

Fig. 9. The individual program of feeding.

\section{THE AdAPTIVE SYSTEM}

The feeding system can be adapted to the different calves using an intelligent algorithm to identify the individual characteristics useful in mixture preparation [10]. The numbers visits to the feeding station, the feeding speed, the frequencies of visits and the body movement during feeding are most important elements in evaluation of health condition. The number of visits is more important than the amount consumed per day and / or consumption rate. More visits indicate an active calf. The amount of the concentrate and the additive is prepared according to the weight of the calf, speed drinking, calf age, group, behaving during the feeding process, the number of visits. Those parameters can be inputs for a diagnosis system which classified calves during the feeding process. The output parameters are the recipes prepared according to the weight, health condition reason to establish growing of calf for meat or for reproduction. The speed of drinking from the teat is another parameter which gave information about the condition of the calf. If the speed is slow the animal has a health problem and the system can increase or decrease the feeding time as well adding of additives or vitamins. The flowmeter is used to record the feeding speed. The numbers of visits to the feeding station are collected via the RFID sensor. The body movement during the feeding process is acquired with the microwave motion digital sensor or via force pressure sensors on the floor.

Using fuzzy algorithm, the automatic feeding system can be individualized for each group of calves [11], [12]. In the fuzzy logic system, the input variables are gathered with the logical operators (OR, AND) to form a fuzzy set. The rules are created with an IF - THEN method for the selection of the control system. A fuzzy inference system to classified is proposed because it uses fuzzy set theory to map inputs as features to be fuzzy classified in outputs. The output variables represent the recipes number corresponding to a known composition and quantity of mixture. Using Sugeno tip 0 inference method in MATLAB fuzzy logic system, the fuzzy membership functions are triangular in inputs and singletons in output.

The inputs proposed for the fuzzy system are: Group, Age, Weight, Behavior and the Feeding Speed. In output the parameters are Recipes (Table I).

TABLE I: THE INPUT AND OUTPUT PARAMETER OF THE FUZZY SET

\begin{tabular}{|l|l|l|}
\hline 1. & Group & Unhealthy, Healthy, Big \\
\hline 2. & Age (month) & First, Second, Third \\
\hline 3. & Weight & Underweight, Normal, Over Weight \\
\hline 4. & Behavior (previous fed) & Sleepy, Normal, Agitate \\
\hline 5. & Speed (previous fed) & Slow, Normal, Fast \\
\hline 6. & Recipe (Output) & $1,2,3,4$ \\
\hline
\end{tabular}

Where recipe is the mixture preparation with water and: 1 . powder milk, 2- powder milk with vitamin 3- powder milk with drugs A, 4- powder milk with drug B

For each recipe system predicts a mixture amount with milk powder, vitamins and drug amount.

Each input parameter has a linear evolution in time and the membership function have a triangular form.

Each input is measured as follow:

Group - interval of data; Age - months or days; Weight $\mathrm{kg}$; Behavior - number of motions and Speed - volume of 
mixture [cm3]. The input coefficient of the membership functions is identified after a cluster method of data analysis.

An example of combination using the four input variables with each other and the logical operators can be:

If Behavior is Agitate and Speed is Slow and Age is First and Weight is Underweight and Group is Healthy Than the Recipes is 2

The rules can identify as the calf is newborn and it is not used with the automatic feeder system. The Output is computed using formula 2.

$$
\text { Output }=\frac{\sum_{i=0}^{N} z_{i}{ }^{*} w_{i}}{\sum_{i=1}^{N} w_{i}}
$$

$\mathrm{N}$-number of rules

wi - the fuzzy coefficient

$\mathrm{zi}$ - degree of membership

The Recipe output represent the class of calf and the next mixture is prepared according to those indications. According to the calf health condition the system increase or decrees the feeding time.

The fuzzy system is simulated in MatLab using FIS Editor. The membership function of the inputs and the singleton of the output are represented in Fig. 10.

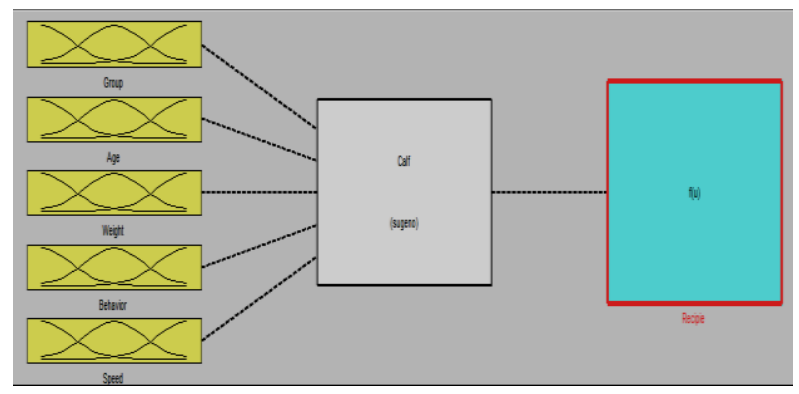

Fig. 10. The Input and output of sugeno fuzzy system simulated in FIS (Matlab).

The membership function is triangular and the fuzzy combination operator is AND, the method used is the maximum aggregation.

\section{RESULTS}

The numbers of rules are counted function of the memberships numebrs for each input.

The system has nine groups of rules function of the calf Age and Group (TableII).

TABLE II: THE RULES INPUTS

\begin{tabular}{|l|l|l|}
\hline $\begin{array}{l}\text { Rulea } \\
\text { numbers }\end{array}$ & Group input & Age input \\
\hline R11 & Group - Unhealty & Age - First \\
\hline R12 & Group - Unhealty & Age - Second \\
\hline R13 & Group - Unhealty & Age - Third \\
\hline R21 & Group - Healty & Age - First \\
\hline R22 & Group - Healty & Age - Second \\
\hline R23 & Group - Healty & Age - Third \\
\hline R31 & Group - Big & Age - First \\
\hline R32 & Group - Big & Age - Second \\
\hline R33 & Group - Big & Age - Third \\
\hline
\end{tabular}

The fuzzy rules are introduced in ANFIS system generated in MATLAB. Some exemples of rules are presented in Fig. 11. The rules can be introduced function of demands and the coeficients of membership function depends of the system test results.

\section{If (Group is $\mathrm{mf3}$ ) and (Age is mf1) and (Weight is $\mathrm{mf} 1$ ) and (Behavior is mf1) and (Speed is mf2) then (Recipie is 1) (1) 3. If (Group is $\mathrm{mf2}$ ) and (Age is $\mathrm{mf3}$ ) and (Weight is $\mathrm{mf1}$ ) and (Behavior is $\mathrm{mf3}$ ) and (Speed is $\mathrm{mf2}$ ) then (Recipie is 5) (1) 4. If (Group is $\mathrm{m} / 3$ ) and (Age is $\mathrm{m} / 3$ ) and (Weight is $\mathrm{mf3}$ ) and (Behavior is $\mathrm{mf3}$ ) and (Speed is $\mathrm{mf2}$ ) then (Recipie is 2) (1) 5. If (Group is $\mathrm{m}$ 2) and (Age is $\mathrm{m}$ 2) and (Weight is $\mathrm{mf1}$ ) and (Behavior is $\mathrm{mf1}$ ) and (Speed is $\mathrm{m}$ (3) then (Recipie is 3) (1) 6. If (Group is $\mathrm{mfl}^{\prime}$ ) and (Age is $\mathrm{mfl}^{\prime}$ ) and (Weight is $\mathrm{mfl}^{\mathrm{f}}$ ) and (Behavior is $\mathrm{mfl}^{1}$ ) and (Speed is $\mathrm{mfl}$ ) then (Recipie is 1) (1) 7. If (Group is mf1) and (Age is mf2) and (Weight is mfl) and (Behavior is mf3) and (Speed is mf1) then (Recipie is 2) (1) 8. If (Group is $\mathrm{mf}^{\prime}$ ) and (Age is $\mathrm{mf2}$ ) and (Weight is mf1) and (Behavior is $\mathrm{mf3}$ ) and (Speed is $\mathrm{mf2}$ ) then (Recipie is 2) (1) 9. If (Group is $\mathrm{mf1}$ ) and (Age is $\mathrm{m}$ 2) and (Weight is $\mathrm{mf1}$ ) and (Behavior is $\mathrm{mf2}$ ) and (Speed is $\mathrm{mf2}$ ) then (Recipie is 2) (1) \\ Fig. 11. The Combinations of the rules in the suggested fuzzy system.}

The memberships functions simulation of fuzzy system is shown in Fig. 12.

Related to the calf age number mixture quantities differ. All of this is written in the recipe output values of fuzzy system.

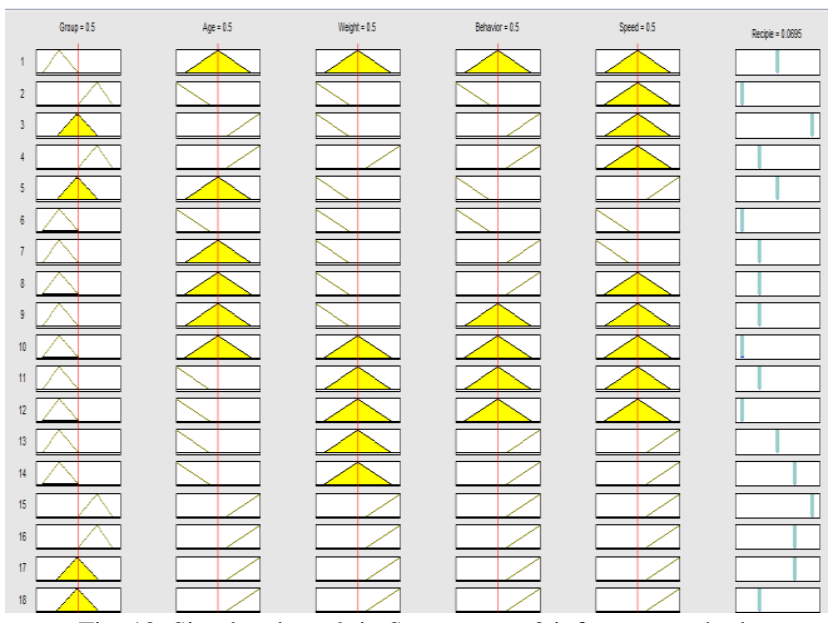

Fig. 12. Simulated result in Sugeno type 0 inference method.

The behavior of calf during feeding can be replaced by the number of visits to the feeding station. The results of the ANFIS simulation has a fractional number which must be approximated with the recipe number. For example, if the output number is 2, 4 the user known as the calf is newborn and it isn't in the normal parameters. The system chooses the recipe number 2 and if after some few feeding process finished abnormally, the system should choose the recipe number 3 (with drug).

The membership coefficients must be obtained after the cluster algorithm applied on the inputs parameters. Those results will be presented in the next paper.

\section{CONCLUSION}

The system presented in this paper is a particular case developed to use two feeding station in order to fed two calves in the same time and to test the many methods to reduce the assistant activity. This system is developed with an individual program of feeding in which each calf has own inputs parameters.

Automatic feeding system makes the process of weaning calves easier because the quantities of milk intake is reduced 
gradually. This reduces the calf stress, which will reduce the incidence of pneumonia and post-weaning diseases. The farmers must continue to pay special attention to basic elements like a good airflow, colostrum management, and ensuring a clean and dry environment. It is very important to maintain contact with the calves to identify which one may need individual medical attention.

\section{REFERENCES}

[1] M. Fujiwara, J. Rushen, and A. M. de Passillé, "Dairy calves' adaptation to group housing with automated feeders," Appl. Anim Behav Sci, vol. 158, pp. 1-7, 2014.

[2] F. Soberon, E. Raffrenato, R. W. Everett, and M. E. Van Amburgh, "Preweaning milk replacer intake and effects on long-term productivity of dairy calves," J. Dairy Sci, vol. 95, pp. 783-793, 2012.

[3] Lely Dairy, "Equipment, Barn, milk and feeding solutions. Create the future for your dairy farm," [Online]. Available: http:// www.lely.com

[4] D. D. SalooKolayi, A. T. Yansari, and S. H. Nasseri, "Application of fuzzy optimization in diet formulation," The Journal of Mathematics and Computer Science, vol. 2, no. 3, pp. 459-468, 2011.

[5] S. Sivamani, H. Kim, C. Shin, J. Park, and Y. Cho, "Towards a balanced nutrition system using fuzzy logic in livestock," Contemporary Engineering Sciences, vol. 9, no. 29, pp. 1437 $1445,2016$.

[6] A. Oluwatoyin and O. Adedoyin, "Design of a fuzzy expert based system for diagnosis of cattle diseases," International Journal of Computer Applications \& Information Technology, vol. I, no. III, pp. 93-98, November 2012.

[7] M.-B. Jensen, "Computer- controlled milk feeding of dairy calves: The effects of number of calves per feeder and number of milk portions on use of feeder and social behavior," J. Dairy Sci, vol. 87, pp. 428-3438.

[8] M. Olaniyi, A. F. Salami, O. O. Adewumi, and O. S. Ajibola, "Design of an intelligent poultry feed and water dispensing system using fuzzy logic control technique," Control Theory and Informatics, vol. 4, no. 9 , pp. 61-72, 2014

[9] S. Tasdemir , A. Urkmez, and S. Inal, "A fuzzy rule-based system for predicting the live weight of Holstein cows whose body dimensions were determined by image analysis," Turk J Elec Eng \& Comp Sci, vol. 19, no. 4, pp. 689-703, 2011

[10] Livestock systems research manual. [Online]. Available: http://www.fao.org/wairdocs/ilri/x5469e/x5469e0a.htm
[11] V. Ionescu and M. Hnatiuc, "Fetal heart rate detection and monitoring from noninvasive abdominal ECG recordings," The 5th IEEE International Conference on E-Health and Bioengineering - EHB 2015, November 19-21, 2015.

[12] M. Hnatiuc, A. Belconde, and F. Kratz, Location of a person by means of sensors' network, ARTIPED 2010, IEEE Xplorer Proceedings, pp. $301-305$

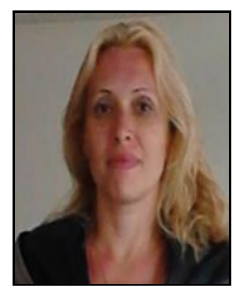

Mihaela Hnatiuc was born on 10th January, 1972 in Bacau. She graduated "Gh. Asachi" Technical University of Iasi, Faculty of Telecommunications and Electronics, Romania, in 1995 and then master degree and $\mathrm{Ph} . \mathrm{D}$ in electronics field at the same university.

She worked five years as a design engineer in electronics and then as a researcher in the same field in Romania and France. Since 2007, she works at Constanta Maritime University as Associate Professor. She has a total of 43 publications in journals and conference proceeding and eight books in electronic domain. She coordinates students team in robotics and electronics contents, with remarkable results.

Mihaela Hnatiuc is member at IEEE and AFCEA societies. The main research field are: robotics, artificial intelligence, sensors and microsystems. She was director of two international grants and members in many interdisciplinary projects.

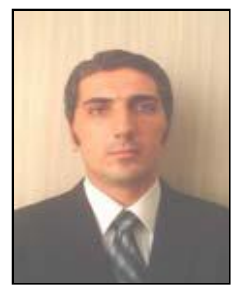

Mugurel Caracostea was born in Constanta on 23rd March 1976. He graduated Naval Academy "Mircea cel Batran" Constanta, Marine Engineering and Navigation in 1999, Romania.

officer and OOW. Since 2007 he worked as technical manager at JJ Marine for three years, IT specialist at Constantugs for one year. From 2009 till present as area sales manager for Catalonia Inox in South East Romania and in parallel from 2015 as a teacher in Energetic Technical College Constanta. He wrote a book as co-author with M. Hnatiuc and C. J. Iov "Unelte de programare in instrumentatie virtuala - descriere si aplicatii", Ed Nautica 2016.

Mugurel Caracostea is member in various interdisciplinary projects. 